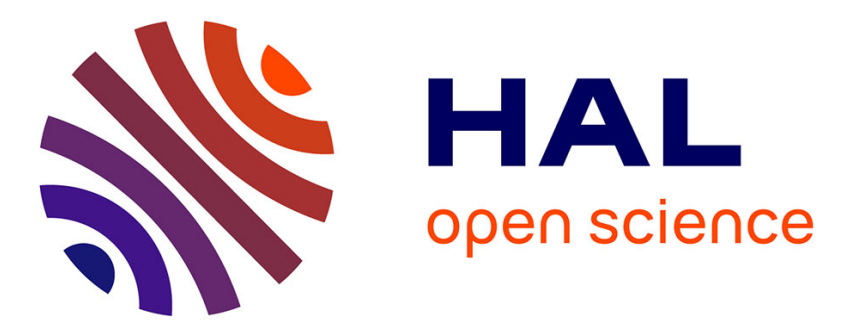

\title{
Continuous-wave operation above room temperature of GaSb-based laser diodes grown on $\mathrm{Si}$
}

Jean-Rémy Reboul, Laurent Cerutti, Jean-Baptiste Rodriguez, Pierre Grech, Eric Tournié

\section{- To cite this version:}

Jean-Rémy Reboul, Laurent Cerutti, Jean-Baptiste Rodriguez, Pierre Grech, Eric Tournié. Continuous-wave operation above room temperature of GaSb-based laser diodes grown on Si. Applied Physics Letters, 2011, 99 (12), pp.121113. 10.1063/1.3644983 . hal-00641322

\section{HAL Id: hal-00641322 \\ https://hal.science/hal-00641322}

Submitted on 15 Nov 2011

HAL is a multi-disciplinary open access archive for the deposit and dissemination of scientific research documents, whether they are published or not. The documents may come from teaching and research institutions in France or abroad, or from public or private research centers.
L'archive ouverte pluridisciplinaire HAL, est destinée au dépôt et à la diffusion de documents scientifiques de niveau recherche, publiés ou non, émanant des établissements d'enseignement et de recherche français ou étrangers, des laboratoires publics ou privés. 


\title{
Continuous-wave operation above room temperature of GaSb-based laser diodes grown on $\mathbf{S i}$
}

\author{
J. R. Reboul, L. Cerutti, ${ }^{a}$ J. B. Rodriguez, P. Grech, and E. Tournié \\ Institut d'Electronique du Sud-UMR 5214 CNRS, Université Montpellier 2, Place Eugène Bataillon, \\ 34095 Montpellier Cedex 5, France
}

(Received 9 May 2011; accepted 10 September 2011; published online 23 September 2011)

\begin{abstract}
We have investigated specifically designed GaSb-based laser diodes epitaxially grown on a $\mathrm{Si}$ substrate. We demonstrate continuous-wave operation of these laser diodes emitting near $2 \mu \mathrm{m}$ up to $35^{\circ} \mathrm{C}$ with several $\mathrm{mW} /$ facet output powers, limited by our experimental setup. Our results open the way to direct monolithic III-V/Si integration. (C) 2011 American Institute of Physics. [doi:10.1063/1.3644983]
\end{abstract}

There is currently a lot of interest in integrating III-V semiconductor alloys and devices on silicon in order to combine their remarkable intrinsic properties with the very advanced silicon technology. Numerous applications such as, e.g., very high speed transistors, photonic-integrated circuits (PICs), or integrated sensors, would benefit from such developments. These last applications call in particular for the realization of integrated optoelectronic devices such as photodetectors and/or laser diodes (LDs).

Two options have been used so far for achieving III-V LDs integration: die bonding and heterogeneous epitaxy. If remarkable progress has been made in the last couple of years with die bonding of InP-based LDs (Ref. 1), it remains unclear whether this technique can be used on a large scale. Heterogeneous epitaxy in contrast would definitely allow large-scale fabrication and direct integration, but it has proven difficult due to the conjunction of large lattice-, thermal-, and polaritymismatches. ${ }^{2}$ Recently, however, it has been shown that the GaSb-based semiconductor alloys grown on Si by molecularbeam epitaxy (MBE) exhibit a particular relaxation mode: strain relaxation occurs by the formation of pure misfit dislocations arranged in a two-dimensional network confined at the III-Sb/Si interface. ${ }^{3,4}$ This particular relaxation mode leads to a highly defective interface but to an improved crystal quality of the III-Sb layer grown atop without resorting to thick buffer layers. ${ }^{5,6}$

III-Sb compound semiconductors thus appear to be very attractive for the integration of III-V devices on a Si platform. We have indeed recently demonstrated laser operation of GaSb-based LDs at room temperature (RT) in pulsed regime around $2.3 \mu \mathrm{m}$ and $1.55 \mu \mathrm{m},{ }^{7,8}$ wavelengths of interest for sensing and PIC applications, respectively. The laser structures were grown on GaSb buffer layers as thin as $1 \mu \mathrm{m}$. The device technology used to fabricate the LDs was a conventional ridge scheme with the $p$-contact taken on the ridge and the $n$-contact taken directly on the back of the Si substrate. Such a scheme drives the current to flow through the highly defective $\mathrm{Si} / \mathrm{III}-\mathrm{Sb}$ interface. This resulted in a high turn-on voltage $\left(\mathrm{V}_{\mathrm{d}}=3 \mathrm{~V}\right)$ and to limited LDs performances. In this letter, we propose and study in details new GaSb-

\footnotetext{
${ }^{\text {a) }}$ Author to whom correspondence should be addressed. Electronic mail: cerutti@univ-montp2.fr.
}

based LDs designed to operate in the continuous wave (cw) regime when grown on $\mathrm{Si}$.

The new design aims, in particular, at avoiding driving the current through the $\mathrm{Si} / \mathrm{III}-\mathrm{Sb}$ interface. It is then necessary to take both contacts in the III-V semiconductor, i.e., the bottom contact has to be located somewhere inside the buffer layer. The structure should thus be designed in such a way to allow etching through the whole laser structure down to the buffer layer. To this aim we propose to insert a thin In $\mathrm{As}_{0.92} \mathrm{Sb}_{0.08}$ layer inside the buffer layer. This layer brings forth several advantages. It is lattice-matched to GaSb. n-type $\mathrm{InAs}_{0.92} \mathrm{Sb}_{0.08}$ presents a very low contact-resistance and a high electrical conductivity in comparison with n-type GaSb. ${ }^{9}$ In addition, it offers a high wet-etching selectivity (>100) with GaSb. ${ }^{10,11}$ This allows keeping a thin buffer layer $(\sim 1 \mu \mathrm{m})$ which is an asset of the III-Sb compounds grown on highly mismatched substrates. However, InAs ${ }_{0.92} \mathrm{Sb}_{0.08}$ exhibits also a high absorption coefficient at wavelengths shorter than $3 \mu \mathrm{m}$. Its position in the structure will result from a compromise between a reduced overlap with the optical mode and practical buffer layers and technology process.

The laser structure was grown by solid-source MBE in a system equipped with both As- and Sb-valved cracker cells. In order to prevent the formation of anti-phase domains, offaxis (001) n-type silicon substrates were chosen with a $7^{\circ}$ miscut toward the [110] direction. The preparation of the $\mathrm{Si}$ substrates and the growth initiation to form the $\mathrm{Si} / \mathrm{III}-\mathrm{Sb}$ interface are described in Ref. 7. After growth of an AlSb nucleation layer, 200-nm Te-doped GaSb, 150-nm Te-doped InAs ${ }_{0.92} \mathrm{Sb}_{0.08}$, and 800-nm Te-doped GaSb were grown in sequence. $n$-type doping resulted in net free-electron densities around $1 \times 10^{18} \mathrm{~cm}^{-3}$ and $5 \times 10^{18} \mathrm{~cm}^{-3}$ in the GaSb and $\mathrm{InAs}_{0.92} \mathrm{Sb}_{0.08}$ layers, respectively. After completion of this composite buffer layer, a typical GaSb-based LD was grown with $1.5 \mu \mathrm{m}$ thick $\mathrm{Al}_{0.9} \mathrm{Ga}_{0.1} \mathrm{As}_{0.07} \mathrm{Sb}_{0.93}$ cladding layers. The active region is made of two compressively strained 9-nm wide $\mathrm{Ga}_{0.75} \mathrm{In}_{0.25} \mathrm{As}_{0.05} \mathrm{Sb}_{0.95}$ quantum wells separated by $30-\mathrm{nm}$ thick $\mathrm{Al}_{0.25} \mathrm{Ga}_{0.75} \mathrm{As}_{0.03} \mathrm{Sb}_{0.97}$ barrier layers. It is embedded in between two 200-nm thick $\mathrm{Al}_{0.25} \mathrm{Ga}_{0.75} \mathrm{As}_{0.03} \mathrm{Sb}_{0.97}$ layers. The laser structure is completed with a $300 \mathrm{~nm}$ highly $p$-doped GaSb top-contact layer. The band structure of the whole laser structure is displayed 


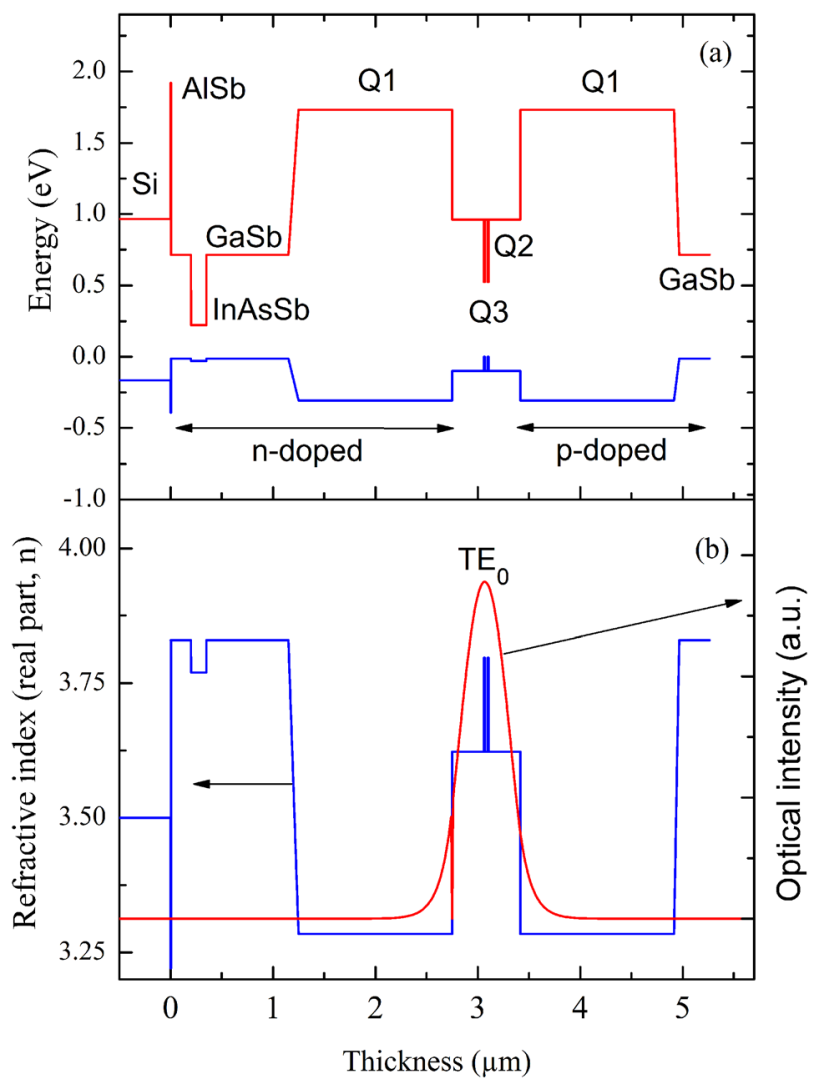

FIG. 1. (Color online) (a) Schematic energy-band diagram of the Sb-based laser diode structure grown on Si. Q1, Q2, and Q3 labels stand for $\mathrm{Al}_{0.9} \mathrm{Ga}_{0.1} \mathrm{As}_{0.08} \mathrm{Sb}_{0.92}, \mathrm{Al}_{0.25} \mathrm{Ga}_{0.75} \mathrm{As}_{0.02} \mathrm{Sb}_{0.98}$, and $\mathrm{Ga}_{0.75} \mathrm{In}_{0.25} \mathrm{As}_{0.06} \mathrm{Sb}_{0.94}$ quaternary alloys, respectively; (b) real part of the refractive index profile in the direction perpendicular to the layers with the calculated intensity of the fundamental $\mathrm{TE}_{0}$ mode in the waveguide.

in Fig. 1. The design of this laser is given for an emission around $2 \mu \mathrm{m}$. Moreover, Fig. 1 presents both variation of the real part of the optical index and the calculated $\mathrm{TE}_{0}$ optical mode. In this configuration, we have calculated that the overlap between the fundamental optical mode and the narrowgap $\operatorname{InAs}_{0.92} \mathrm{Sb}_{0.08}$ layer is as low as $10^{-5} \%$ which shows that the impact of its absorption can be neglected.

Ridge LDs were processed using standard photolithography and wet etching. Two types of LDs were fabricated from the same wafer. In both cases, the $p$-contacts were taken on the top ridge. In the conventional LDs, the $n$-contact was taken on the back of the Si substrate (the so-called "topbottom" contact scheme), while in the new LDs, the $n$-contact was taken on the $\operatorname{InAs}_{0.92} \mathrm{Sb}_{0.08}$ layer located within the buffer layer (the so-called "top-top" contact scheme). In this last case, we etched through the whole structure down to the $\operatorname{InAs}{ }_{0.92} \mathrm{Sb}_{0.08}$ layer which has then a double role: etch-stop layer and contact layer. Electrical insulation was obtained using 500-nm-thick $\mathrm{Si}_{3} \mathrm{~N}_{4}$ dielectric layers deposited by plasma-enhanced chemical vapor deposition. Contact metals were $\mathrm{Cr}-\mathrm{Au}$ for III-V materials and AuGeNi for the Si substrate. Laser cavities were formed by simple cleaving of the facets which is an issue with a Si substrate. Compared to our previous work, ${ }^{7,8}$ thinning the wafer down to $50 \mu \mathrm{m}$ improves the cleavage yield. All facets have been inspected by optical microscopy and only the best cavity LDs exhibiting crack-free facets were mounted and tested since we have

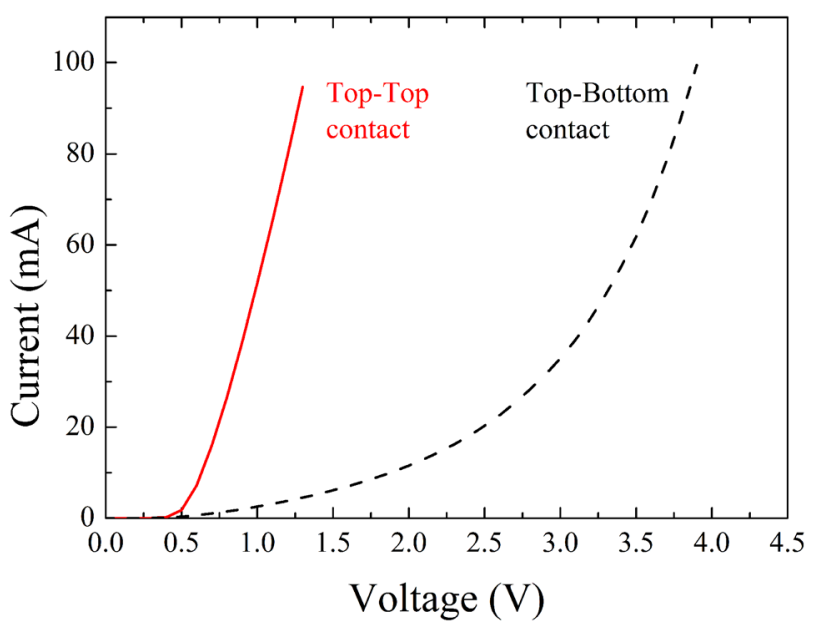

FIG. 2. (Color online) I-V characteristics of $8 \mu \mathrm{m} \times 2 \mathrm{~mm}$ laser diodes for the top-bottom (dash line) and top-top (solid line) contact schemes.

observed that cracked facets prevent lasing. No optical treatment was applied to the facets. The devices were then soldered epi-side up with indium on $\mathrm{Cu}$ heat sinks. The $n$-contact is typically about $40 \mu \mathrm{m}$ away from the ridge.

Figure 2 shows the current-voltage characteristics of the different LDs. In the "top-bottom" configuration (dotted line in Fig. 2), where the current flows through the Si/III-Sb interface, measurements give a high turn-on voltage $\mathrm{V}_{\mathrm{d}} \sim 2.8 \mathrm{~V}$ and a high series resistance $\mathrm{R}_{\mathrm{S}} \sim 11 \Omega$. In contrast, measurements in the "top-top" configuration (solid line in Fig. 2), i.e., between the laser ridge and the $\mathrm{InAs}_{0.92} \mathrm{Sb}_{0.08}$ contact layer, reveal a strong improvement of the electrical properties with a drastic reduction of $\mathrm{V}_{\mathrm{d}}$ down to $\sim 0.7 \mathrm{~V}$ and of $\mathrm{R}_{\mathrm{S}}$ down to $\sim 6 \Omega$. The value of the turn-on voltage is comparable to the one measured on LDs directly grown on GaSb substrates and emitting in the same wavelength range. ${ }^{12,13}$ These results show that the highly conductive $\operatorname{InAs}_{0.92} \mathrm{Sb}_{0.08}$ layer allows the current flowing horizontally from the $n$-contact pad to the ridge region even though they are $40 \mu \mathrm{m}$ apart. Further, they confirm that driving the current through the III-Sb/Si interface is a limiting factor in the conventional contact scheme. Indeed, the presence of a high density of defect at the III-Sb/Si interface combined with the AlSb potential barrier (Figure 1(a)) dramatically degrades the electrical performance.

Next, we performed electro-optical characterizations of the LDs. First characterization were done on pulsed regime $(21 \mathrm{kHz}-100 \mathrm{~ns})$ at $\mathrm{RT}$ with a $8-\mu \mathrm{m}$ wide ridge and $2 \mathrm{~mm}$ long cavity LD. Threshold current densities as low as $900 \mathrm{~A} / \mathrm{cm}^{2}$ were obtained in "top-top" configuration. It was around $1.5 \mathrm{kA} / \mathrm{cm}^{2}$ in the "top-bottom" scheme which precluded $\mathrm{cw}$ operation in this configuration. Fig. 3 shows the L-I-V curves obtained in $\mathrm{cw}$ at various temperatures for a "top-top" LD. The turn-on voltage $\mathrm{V}_{\mathrm{d}}$ is close to $\sim 0.8 \mathrm{~V}$ at $20^{\circ} \mathrm{C}$, and it is mainly due to the bandgap $(\sim 0.6 \mathrm{eV}$ at $2 \mu \mathrm{m})$. $\mathrm{CW}$ laser operation is achieved up to $35^{\circ} \mathrm{C}$, the highest temperature allowed by our experimental setup. The $\mathrm{cw}$ output power measured under a maximum drive current of $350 \mathrm{~mA}$ varies between 8 $\mathrm{mW} /$ facet and $2 \mathrm{~mW} /$ facet when the temperature is ramped from $10^{\circ} \mathrm{C}$ to $35^{\circ} \mathrm{C}$. The external quantum efficiency $\eta_{\mathrm{d}}$, obtained from the slope of the L-I curves, changes from $16 \%$ to $12 \%$ in this temperature range. Note that $\eta_{\mathrm{d}}$ remains 


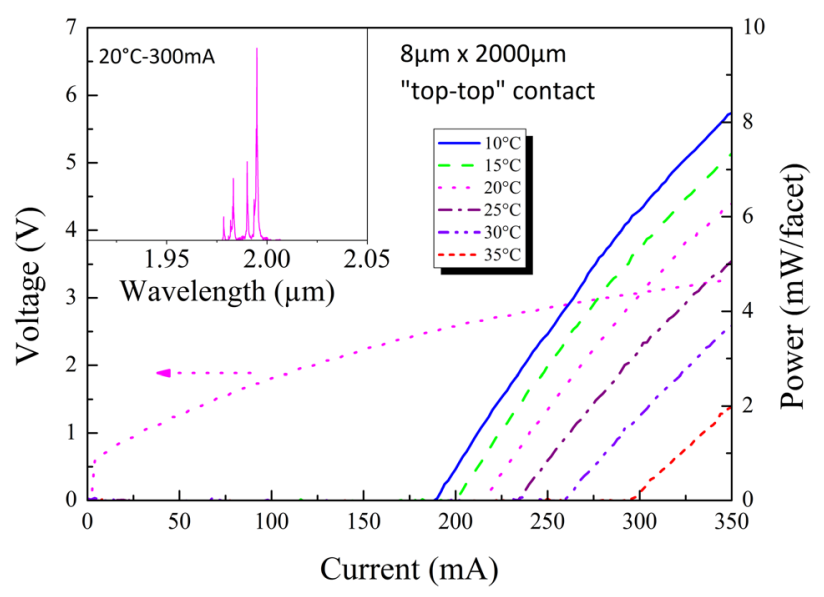

FIG. 3. (Color online) CW output-power characteristics at $2 \mu \mathrm{m}$ for different temperatures and the voltage-current curve at $20^{\circ} \mathrm{C}$. The inset shows the lasing spectrum taken at $20^{\circ} \mathrm{C}$ under $300 \mathrm{~mA} \mathrm{CW}$ injection.

constant for each measurement temperature (Fig. 3) which shows that we have not yet reached the thermal roll-over and that the output-power measurements are also setup limited. The so-called $\mathrm{T}_{0}$ temperature which characterizes the evolution with temperature of the threshold current intensity varies from $\sim 80 \mathrm{~K}$ below $20^{\circ} \mathrm{C}$ to $\sim 40 \mathrm{~K}$ at higher temperatures. These values are slightly lower than that obtained with state of the art LDs grown on GaSb. ${ }^{12,13}$ Finally, the inset in Figure 3 displays the emission spectrum taken at $20^{\circ} \mathrm{C}$ under 300 $\mathrm{mA} \mathrm{cw}$ current drive. The main mode peaks at around $2 \mu \mathrm{m}$ as expected from the composition of the active region.

To further characterize these LDs, we have measured the device modal gain spectra at several currents below the threshold. Modal gain spectra were obtained using the Hakki-Paoli method. ${ }^{14}$ Fig. 4 shows modal gain spectra taken at 3 different currents at $20^{\circ} \mathrm{C}$ with a "top-top" LD. The total optical losses can be determined from the low energy part of the modal gain spectra where the spectra measured at different currents converge. For photon energies near $0.61 \mathrm{eV}$, i.e., just below the $\mathrm{e}_{1}-\mathrm{hh}_{1}$ transition in the quantum wells, the gain spectra converge to total optical losses around $\sim 32 \mathrm{~cm}^{-1}$ (Fig. 4). Since, as described above, we have crack-free facets, the mirror losses can calculated using the usual equation ${ }^{15}$ which gives about $12 \mathrm{~cm}^{-1}$ for a 2-mm-long LD. This leaves a value of $\sim 20 \mathrm{~cm}^{-1}$ for internal losses. This value is within a factor of 5-10 higher than that obtained in the case of similar lasers grown directly on the GaSb substrate. ${ }^{12,13,16}$ These high optical losses are mainly attributed to optical scattering within the waveguide due to residual threading dislocations originating from the $\mathrm{Si} / \mathrm{III}-\mathrm{Sb}$ interface. Optimization of the growth process is under way to further improve LD performances.

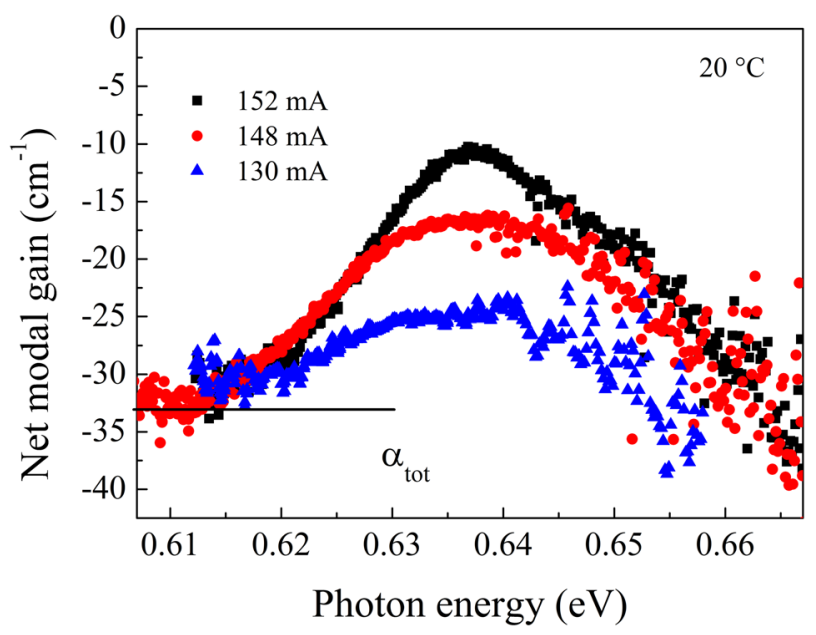

FIG. 4. (Color online) Sub-threshold gain spectra taken at $20^{\circ} \mathrm{C}$ from a $8 \mu \mathrm{m} \times 2 \mathrm{~mm}$ long GaSb-based "top-top" laser diode grown on $\mathrm{Si}$.

In conclusion, we have demonstrated cw operation of GaSb-based LDs directly grown onto silicon. Given the versatility of the III-Sb compound semiconductor technology which covers the whole mid- and far-infrared wavelength range and which offers the highest electron- and holemobilities, our results open the route to the direct monolithic integration of III-V devices with a Si platform.

${ }^{1}$ For a recent review see, e.g., D. Liang and J. E. Bowers, Nature Photon. 4, 511 (2010).

${ }^{2}$ H. Kroemer, J. Cryst. Growth 81, 193 (1987).

${ }^{3}$ S. H. Huang, G. Balakrishnan, A. Khoshakhlagh, L. R. Dawson, and D. L. Huffaker, Appl. Phys. Lett. 93, 071102 (2008).

${ }^{4}$ Y. H. Kim, Y. K. Noh, M. D. Kim, J. E. Oh, and K. S. Chung, Thin Solid Films 518, 2280 (2010).

${ }^{5}$ Y. H. Kim, J. Y. Lee, Y. G. Noh, M. D. Kim, S. M. Cho, Y. J. Kwon, and J. E. Oh, Appl. Phys. Lett. 88, 241907 (2006).

${ }^{6}$ A. Jallipalli, G. Balakrishnan, S. H. Huang, A. Khoshakhlagh, L. R. Dawson, and D. L. Huffaker, J. Cryst. Growth 303, 449 (2007).

${ }^{7}$ J. B. Rodriguez, L. Cerutti, P. Grech, and E. Tournié, Appl. Phys. Lett. 94, 061124 (2009).

${ }^{8}$ L. Cerutti, J. B. Rodriguez, and E. Tournié, IEEE Photonics Technol. Lett. 22, 553 (2010).

${ }^{9}$ C. Lauer, O. Dier, and M. C. Amann, Semicond. Sci. Technol. 21, 1274 (2006).

${ }^{10}$ J. P. Perez, A. Laurain, L. Cerutti, I. Sagnes, and A. Garnache, Semicond. Sci. Technol. 25, 045021 (2010).

${ }^{11}$ C. Cervera, J. B. Rodriguez, J. P. Perez, H. Ait-Kaci, R. Chaghi, L. Konczewicz, S. Contreras, and P. Christol, J. Appl. Phys. 106, 033709 (2010).

${ }^{12}$ A. Salhi, Y. Rouillard, J. Angellier, and M. Garcia, IEEE Photonics Technol. Lett. 16, 2424 (2004).

${ }^{13}$ D. Z. Garbuzov, H. Lee, V. Khalfin, R. Martinelli, J. C. Connolly, and G. L. Belenky, IEEE Photonics Technol. Lett. 11,794 (1999).

${ }^{14}$ B. W. Hakki and T. L. Paoli, J. Appl. Phys. 46, 1299 (1975).

${ }^{15}$ G. P. Agrawal and N. K. Dutta, Long Wavelength Semiconductor Lasers (Van Nostrand Reinhold, New York, 1986).

${ }^{16}$ L. Shterengas, G. L. Belenky, A. Gourevitch, J. G. Kim, and R. U. Martinelli, Appl. Phys. Lett. 81, 4517 (2002). 